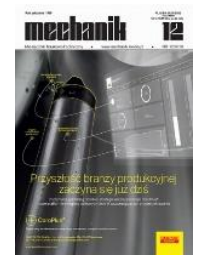

How to cite this article:

Author: Krzysztof Nozdrzykowski

Title of article: „Procedures of determining and realization of reaction forces in an elastic support system for

crankshafts"

Mechanik, No. 12 (2018)

DOI: https://doi.org/10.17814/mechanik.2018.12.201

\title{
Procedures of determining and realization of reaction forces in an elastic support system for crankshafts
}

\section{KRZYSZTOF NOZDRZYKOWSKI *}

Dr hab. inż. Krzysztof Nozdrzykowski prof. AM w Szczecinie, k.nozdrzykowski@am.szczecin.pl,_https://orcid.org/0000-0003-2785-0868 - Akademia Morska w Szczecinie, Szczecin, Polska

The basic elements of an innovative system designed to measure geometric deviations of crankshafts provided with a so-called elastic support system are presented. The support system enables elimination of deflections and elastic deformations of the object measured under the influence of its own weight. The principles of the most suitable support conditions which enable elimination of deflections and elastic deformations of crankshafts under their self-weight were also presented. On the basis of the formulated principles sample calculations of force values of support reactions were performed. This guarantees zero value of deflections on main journals depending on the angle of rotation of the shaft, applying approximated with a mathematical equation applying the calculating method based on the harmonic analysis theory. Then a comparative assessment of the force diagram (the forces were obtained via strength calculations and mathematical model including so called mutual inter-correlation coefficient) was made. The results of comparative analysis showed high correspondence between the compared diagrams. Presented procedures of determining the required forces ensuring elimination of deflections and elastic deformations can be applied to measurements of crankshaft geometrical deviations on the basis of a measuring system with flexible support of a measured object.

KEYWORDS: crankshafts, geometrical deviations, elastic deflections, support conditions, harmonic analysis

\section{Indroduction}

What distinguishes large, in many places supported crankshafts of marine engines from the group of largesize machine elements, is their low rigidity and the resulting high susceptibility to elastic deflections. Therefore, in this type of machine parts, depending on the support conditions, there are elastic deflections with variable sign and value due to changes in shaft rigidity during rotation.

From the point of view of the measurements correctness, an important issue at the stage of size and dimensional crankshaft control is the selection of support conditions eliminating deflection and elastic deformation of the shaft occurring under the influence of its own weight $[8,9]$.

\section{Selection of conditions in the flexible shaft support system}

Taking into account the above observations, an innovative measuring system was developed at the Department of Fundamentals of Machine Construction and Operation, Maritime University of Szczecin, based on the so-called elastic support system of the measured object. By proper selection of reaction forces of support loads relieving the system, it is possible to eliminate deflections and elastic deformations of the shaft [7-9]. The scheme of the most important elements of this system is presented in fig. 1. 


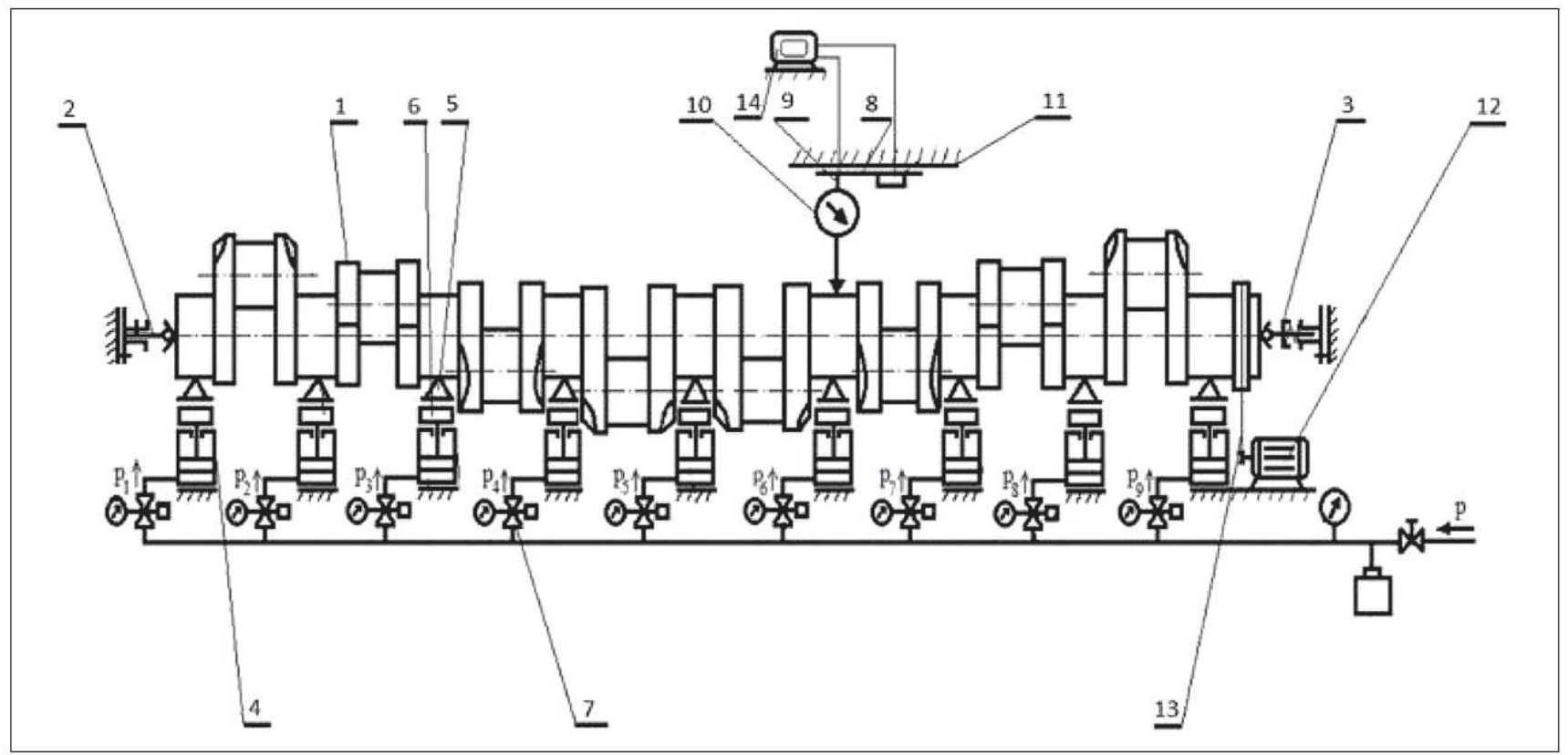

Fig. 1. Diagram of the main elements of the measuring system from the so-called elastic support for the crankshaft: 1 - crankshaft, 2 and 3 - retaining washers, 4 - support with pneumatic cylinder, 5 - prism head, 6 - force sensor, 7 - precision current-controlled valve, 8 - carriage, 9 - tripod, 10 - measuring sensor, 11 - guides, 12 - motor with gear motor, 13 belt transmission, 14 - PC with software

Elastic support system consists of a set of flexible supports, the number and arrangement of which depend on the number and arrangement of the main shafts journals. Each support is equipped with a pneumatic cylinder 4, a prismatic support head 5 and a force sensor 6 . The required values of reaction forces at the contact of the relief support heads with the main pins, ensuring elimination of deflections and elastic deformations of the shaft, carried out by the supports, are monitored in the feedback system by 7 precision controlled valves cooperating with a computer 14 . The appropriate values of reaction forces are previously determined using the available FEM strength calculation software - Nastran 2010 or Inventor Professional 2017. These programs, after modeling the object accepted for testing, allow to make the necessary calculations and determine the support conditions guaranteeing elimination of elastic shaft deflections [8].

TABLE. Required reaction force values guaranteeing zero values of deflections on the journals when the shaft rotation angle changes every $15^{\circ}$, derived from the FEM strength calculation software Nastran FX 2010

\begin{tabular}{|c|c|c|c|c|c|c|c|c|c|c|c|c|c|c|c|c|c|c|c|c|c|c|c|c|c|}
\hline & \multicolumn{25}{|c|}{ Angular value $\left[{ }^{\circ}\right]$} \\
\hline & 0 & 15 & 30 & 45 & 60 & 75 & 90 & 105 & 120 & 135 & 150 & 165 & 180 & 195 & 210 & 225 & 240 & 255 & 270 & 285 & 300 & 315 & 330 & 345 & 360 \\
\hline 1 & 731,6 & 727,5 & 737,5 & 758,9 & 786,0 & 811,6 & 828,7 & 832,9 & 822,9 & 801,5 & 774,3 & 748,8 & 731,6 & 727,5 & 737,5 & 758,9 & 786,0 & 811,6 & 828,7 & 832,9 & 822,9 & 801,5 & 774,3 & 748,8 & 731,6 \\
\hline 2 & 988,5 & 1005,4 & 989,1 & 944,0 & 882,0 & 819,9 & 774,3 & 757,4 & 773,6 & 818,8 & 880,8 & 942,9 & 988,5 & 1005,4 & 989,1 & 944,0 & 882,0 & 819,9 & 774,3 & 757,4 & 773,6 & 818,8 & 880,8 & 942,9 & 988,5 \\
\hline 3 & 871,1 & 823,8 & 822,9 & 868,9 & 949,3 & 1042,6 & 1123,8 & 1171,2 & 1172,0 & 1126,1 & 1045,7 & 952,3 & 871,1 & 823,8 & 822,9 & 868,9 & 949,3 & 1042,6 & 1123,8 & 1171,2 & 1172,0 & 1126,1 & 1045,7 & 952,3 & 871,1 \\
\hline 4 & 1166,3 & 1237,2 & 1253,2 & 1210,0 & 1119,2 & 1005,0 & 898,2 & 827,3 & 811,3 & 854,5 & 945,4 & 1059,5 & 1166,3 & 1237,2 & 1253,2 & 1210,0 & 1119,2 & 1005,0 & 898,2 & 827,3 & 811,3 & 854,5 & 945,4 & 1059,5 & 1166,3 \\
\hline 5 & 847,9 & 796,4 & 795,3 & 844,8 & 931,7 & 1032,7 & 1120,7 & 1172,2 & 1173,3 & 1123,8 & 1036,9 & 935,9 & 847,9 & 796,4 & 795,3 & 844,8 & 931,7 & 1032,7 & 1120,7 & 1172,2 & 1173,3 & 1123,8 & 1036,9 & 935,9 & 847,9 \\
\hline 6 & 1093,0 & 1123,7 & 1108,9 & 1052,5 & 969,8 & 882,7 & 814,7 & 784,1 & 798,9 & 855,2 & 938,0 & 1025,0 & 1093,0 & 1123,7 & 1108,9 & 1052,5 & 969,8 & 882,7 & 814,7 & 784,1 & 798,9 & 855,2 & 938,0 & 1025,0 & 1093,0 \\
\hline 7 & 852,0 & 799,7 & 797,2 & 845,2 & 930,7 & 1030,9 & 1119,0 & 1171,3 & 1173,8 & 1125,9 & 1040,3 & 940,1 & 852,0 & 799,7 & 797,2 & 845,2 & 930,7 & 1030,9 & 1119,0 & 1171,3 & 1173,8 & 1125,9 & 1040,3 & 940,1 & 852,0 \\
\hline $\begin{array}{ll} & \end{array}$ & 1142,2 & 1212,9 & 1231,6 & 1193,3 & 1108,2 & 999,2 & 895,4 & 824,7 & 806,0 & 84,3 & 929,4 & 1038,4 & 1142,2 & 1212,9 & 1231,6 & 1193,3 & 1108,2 & 999,2 & 895,4 & 824,7 & 806,0 & 844,3 & 929,4 & 1038,4 & 1142,2 \\
\hline 9 & 988,1 & 944,1 & 934,0 & 960,4 & 1016,3 & 1086,8 & 1152,8 & 1196,9 & 1207,0 & 1180,6 & 1124,7 & 1054,2 & 988,1 & 944,1 & 934,0 & 960,4 & 1016,3 & 1086,8 & 1152,8 & 1196,9 & 1207,0 & 1180,6 & 1124,7 & 1054,2 & 988,1 \\
\hline 10 & 603,5 & 613,5 & 614,6 & 606,4 & 591,2 & 573,0 & 556,7 & 546,6 & 545,5 & 553,7 & 568,9 & 587,2 & 603,5 & 613,5 & 614,6 & 606,4 & 591,2 & 573,0 & 556,7 & 546,6 & 545,5 & 553,7 & 568,9 & 587,2 & 603,5 \\
\hline
\end{tabular}

Tests carried out previously have shown that to eliminate deflections, all main journals of the shaft should be supported by a set of relief supports, and values of reaction forces at the contact of the heads of supports with journals should change not only along the length of the shaft, but also with the change of shaft rotation angle on the supports.

Sample results of calculations of the force values guaranteeing elimination of shaft deflections implemented for the adopted research object, which was the crankshaft of the eight-cylinder medium-speed engine of the main drive of the Buckau Wolf R8 DV136 vessel, are presented in the table. It was a shaft with a length of 3630 $\mathrm{mm}$ and a weight of $9360 \mathrm{~N}$ with 10 main pins with a diameter of $\varnothing 149 \mathrm{~mm}$. 
The table presents values of the required reaction forces on the journals guaranteeing zero deflection values when the shaft rotation angle changes every $15^{\circ}$, calculated in the program for strength calculations of FEM Nastran FX 2010.

Graphic interpretation of the calculation results is shown in fig. 2.

Results of calculations presented in the polar coordinate system have shown that the force distribution considered in the range of the shaft rotation angle $0 \div 360^{\circ}$ creates an image of a regular ellipse, which in the Cartesian coordinate system corresponds to a function similar to a cosine wave. The criteria for harmonic analysis are used to mathematically describe this function $[1-3,8]$. According to it, the main component of the mathematical notation of a function is the second harmonic component, illustrating the extent, to which this outline is oval.

For values of forces presented in the table, harmonic components were calculated based on the functional relationship in the form:

$$
R(\phi)=R_{0}+\sum_{n=1}^{k} C_{R n} \cos n\left(\phi-\phi_{R_{n}}\right)
$$

where: $R_{0}$ - average value of calculated reaction force; $C_{R n}$ - amplitude of the subsequent $n$-harmonic mathematical record of reaction forces; $\varphi_{R n}$ - phase shift of the subsequent $n$-harmonic mathematical record of reaction forces.

or its corresponding:

$$
R(\phi)=R_{0}+\sum_{n=1}^{k} A_{R n} \cos n \phi+\sum_{n=1}^{k} B_{R n} \sin n \phi
$$

where: $A_{R n}, B_{R n}$ - components of the amplitudes of subsequent $n$-harmonic mathematical record of reaction forces.

Comparative assessment of force value compliance diagrams obtained from strength calculations and mathematical record presented in the form of the trigonometric Fourier series, the measure of which was the so-called mutual intercorrelation coefficient $[4-6,8]$, showed that the value of this coefficient for the set of main journals of the tested shaft was from 0.9542 to 0.9578 . According to J.P. Guilford rating scale for determining the degree of correlation, this corresponds to a very high correlation between the compared charts. According to this assessment scale, degree of dependence between the analyzed graph properties is inevitable.

For example: fig. 3 shows - in polar and Cartesian coordinate systems - the distribution of forces obtained from strength calculations and mathematical record expressed using the trigonometric Fourier series, within the shaft rotation angle range $0 \div 360^{\circ}$ guaranteeing zero deflection values on a selected main spigot (pin No. 1 from the timing wheel side).

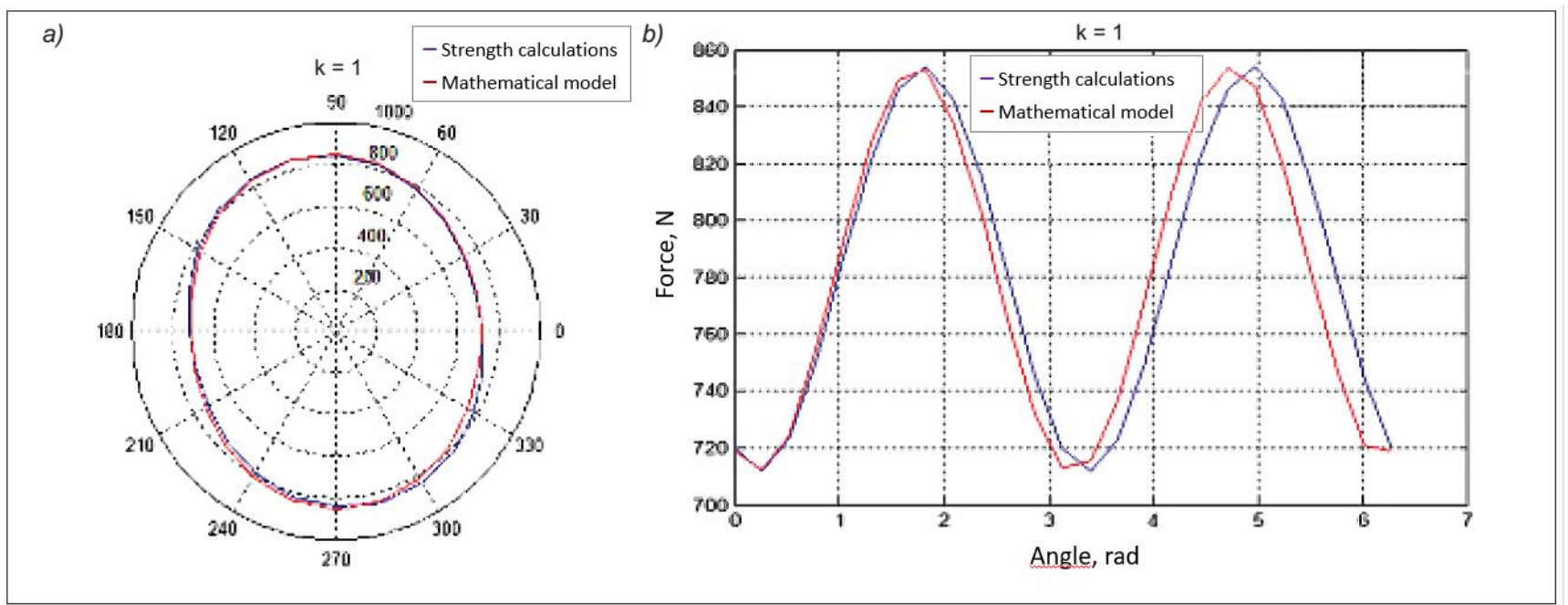

Fig. 2. Distribution of reaction forces guaranteeing zero deflection values on main journals for crankshaft with main journals $149 \mathrm{~mm}$ and crank journals $144 \mathrm{~mm}$ and oval crank arms with dimensions of $252 \times 358 \mathrm{~mm}$, in: $a$ ) polar coordinate system, $b$ ) Cartesian 

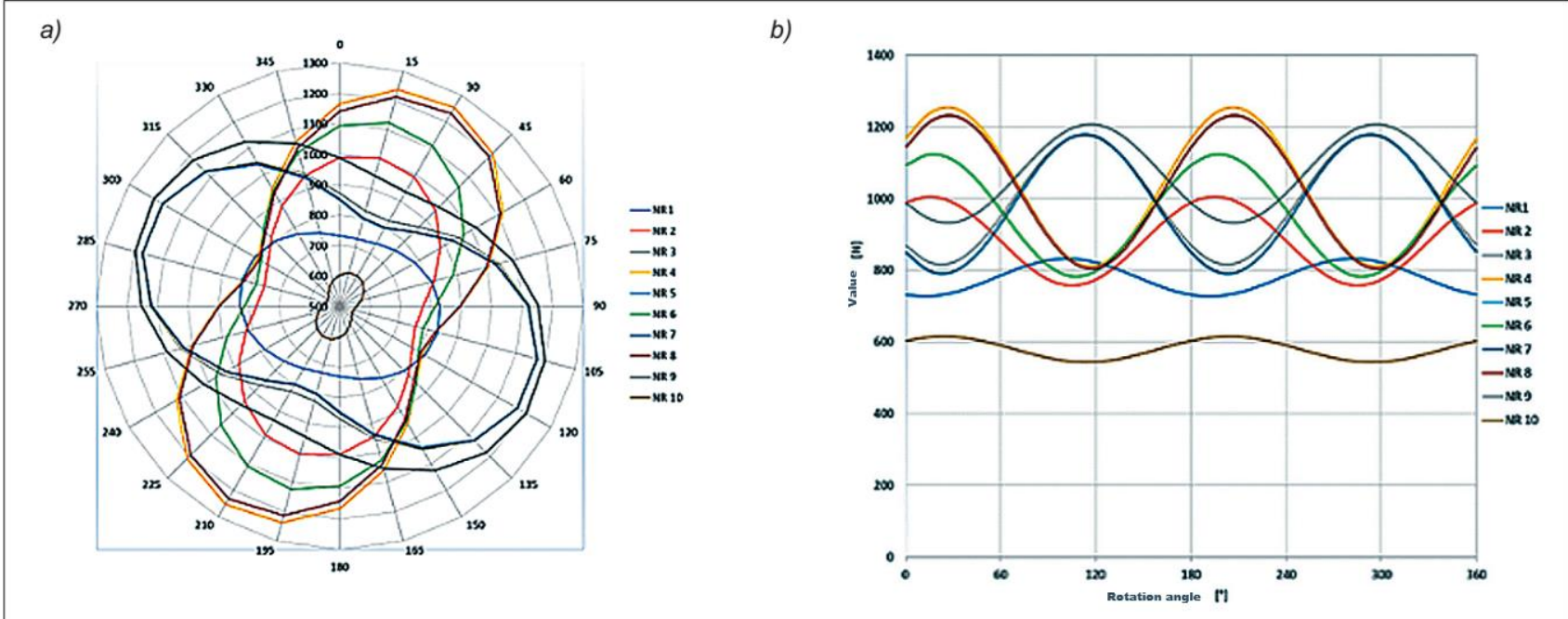

Fig. 3. Distribution of forces within the $0 \div 360^{\circ}$ shaft angle of rotation guaranteeing zero deflection values on the journal No. 1 (counting from the timing wheel side), in the coordinate system: $a$ ) polar, b) Cartesian

\section{Summary}

Presented procedures for determining the required values of reaction forces that guarantee the elimination of deflections and elastic deformations of the shaft have been used in the measurement of crankshaft geometrical deviations, carried out using previously presented measuring system equipped with an elastic support system. The mathematical record of the reaction force value enabled, in a continuous manner, computer supervision of the work of precision controlled valves, through which the inflow of the medium supplying the flexible relief supports is regulated.

Functioning of the system in terms of the correct selection of the required reaction forces eliminating deflection and elastic deformation of the shaft under the influence of dead weight was assessed by measuring deformation of the crank arms, which in shaft measuring techniques is determined by measuring springback. These measurements, carried out using the new method, the so-called symmetrical measurement of crank arm deformations, showed no deflections and elastic deformations of the shaft, which proves the correctness of the selection of required reaction forces and the entire measuring system.

\section{REFERENCES}

[1] Adamczak S. „Odniesieniowe metody pomiaru zarysów okrągłości części maszyn”. Monografie, Studia, Rozprawy. Kielce: Politechnika Świętokrzyska, 1998.

[2] Adamczak S., Makieła W. „Metrologia w budowie maszyn, zadania z rozwiq̨zaniami”. Wyd. II. Warszawa: WNT, 2007.

[3] Adamczak S., Makieła M., Stępień K. "Investigating advantages and disadvantages of the analysis of a geometrical surface structure with the use of Fourier and wavelet transform". Metrology and Measurement Systems. XVII, 2 (2010): 233-244.

[4] Adamczak S., Janecki D., Makieła W., Stępień K. “Quantitative comparison of cylindricity profiles measured with different methods using Legendre-Fourier coefficients". Metrology and Measurement Systems. XVII, 3 (2010): s. 397-404.

[5] Stępień K., Janecki D., Adamczak S. "Investigating the influence of selected factors on results of V-block cylindricity measurements". Measurement. 44/4 (2011): 767-777.

[6] Nozdrzykowski K., Janecki D. “Comparatiye studies of reference measurements of cylindrical surface roundness profiles of large machine components". Metrology and Measurement System. XXI, 1 (2014): s. 67-76.

[7] Nozdrzykowski K. "Prevention of elastic strains in flexible large size machine parts witch the use of elastic support". Machine Dynamics Research. 42, 4 (2015): 111-122.

[8] Nozdrzykowski K. "Metodyka pomiarów geometrycznych odchyłek powierzchni walcowych wielkogabarytowych elementów maszyn na przykładzie wałów korbowych silników okrętowych". Szczecin: Wydawnictwo Naukowe Akademii Morskiej w Szczecinie, 2013.

[9] Sun J., Wang J., Gui C. "Whole crankshaft beam-element, finite-element method for calculating crankshaft deformation and bearing load of an engine". Proceedings of the Institution of Mechanical Engineers. Part. J: Journal of Engineering Tribology. 224 (2010): 299-303. 